\title{
Between-visit variability of small airway obstruction markers in patients with asthma
}

To the Editor:

Clinical trials in patients with airway diseases often use forced expiratory volume in $1 \mathrm{~s}(\mathrm{FEV} 1)$ as the sole physiological outcome measure. However, FEV1 is thought to be insensitive to obstruction of the smaller airways, which may be particularly relevant in asthma [1]. Putative markers of small airway obstruction include measures of airway resistance using impulse oscillometry (IOS) [2] and indices of ventilation heterogeneity derived from multiple-breath inert gas washout (MBW) [3]. We recently showed that increased airway resistance at $5 \mathrm{~Hz}(R 5)$ and $20 \mathrm{~Hz}\left(R_{20}\right)$ is associated with worse asthma control and more frequent exacerbations [4], and FARAH et al. [5] demonstrated that MBW parameters may be responsive to asthma therapy.

In order to conduct clinical trials using these alternative outcome measures, it is necessary to be assured of their repeatability and stability over time. Moreover, an estimate of between-visit variability in the stable state is required so that sample size calculations can be performed. We therefore aimed to determine the between-visit variability of a range of IOS and MBW indices in a group of patients with asthma in the stable state. We investigated between-visit variability over two time intervals, namely 2 weeks and 3 months, in order to encompass the typical lengths of treatment period that are used in clinical trials.

We recruited 18 adults (age $>18$ years) with moderate-to-severe asthma (Global Initiative for Asthma treatment steps 3-5 [6]), diagnosed by a specialist asthma physician in a secondary care setting, according to British Thoracic Society guidelines [7]. The study was approved by the National Research Ethics Committee - East Midlands Leicester, and all participants gave their written informed consent. The participant group comprised nine males and nine females with a mean \pm SD age of $58 \pm 11$ years. All participants were treated with inhaled corticosteroids (1000-2000 $\mu \mathrm{g}$ per day, beclomethasone dipropionate equivalent) and longacting $\beta_{2}$-agonists. 11 patients received maintenance low-dose prednisolone (5-15 mg per day). Postbronchodilator FEV1 was $80.5 \pm 23.0 \%$ predicted with bronchodilator reversibility of $13.5 \pm 16.0 \%$. A previous history of atopy was documented in nine patients. Geometric mean (95\% CI) sputum eosinophil fraction was $2.6 \%(1.1-6.3 \%)$ and the neutrophil fraction was $58.6 \pm 28.2 \%$.

At each study visit, participants completed the six-point Asthma Control Questionnaire [8]. Following administration of a bronchodilator (salbutamol $400 \mu \mathrm{g}$ via a metered-dose inhaler and spacer), IOS, MBW and spirometry were performed at baseline, then at 2 weeks and 3 months following baseline. All study visits took place in the stable state $\geqslant 6$ weeks following any exacerbation of asthma.

IOS was performed using a Jaeger MasterScreen Impulse Oscillometry System (Viasys Healthcare GmbH, Hoechberg, Germany) according to standard guidelines [9]. Participants wore a nose clip and supported their cheeks while an impulse waveform was delivered to their respiratory system via a loudspeaker connected to a mouthpiece, during relaxed tidal breathing. Each test lasted $60 \mathrm{~s}$, with an impulse frequency of $5 \mathrm{~Hz}$, and was repeated in triplicate. The mean value from the triplicate tests was recorded for each IOS parameter.

MBW was performed in triplicate according to current guidelines [3], using the sulfur hexafluoride wash-in method described by HoRSLEY et al. [10]. Participants wore a nose clip and breathed an air mixture containing $0.2 \%$ sulfur hexafluoride, while maintaining a steady respiratory rate of $\sim 12$ breaths per minute and a constant tidal volume of $1 \mathrm{~L}$, using a real-time visual display of inspired volume as a guide. Respiratory flows and exhaled breath sulfur hexafluoride concentrations were monitored using an Innocor photoacoustic gas analyser (Innovision A/S, Odense, Denmark). Once inhaled and exhaled sulfur hexafluoride concentrations had equalised, participants were switched to breathing room air during an expiration and continued breathing at the same respiratory rate and tidal volume. The test was terminated once the end-tidal concentration of sulfur hexafluoride in exhaled breath fell below 1/40th of the original concentration for three consecutive breaths. Lung clearance index (LCI) [3], Scond (conductive ventilation heterogeneity) and Sacin (acinar ventilation heterogeneity) [11] were calculated using custom software written with TestPoint (Measurement Computing Corporation, Norton, MA, USA). 
The intraclass correlation coefficient (ICC) (SPSS Version 20; IBM Corporation, Somers, NY, USA) was calculated for each physiological variable, for the 2-week and 3-month time intervals (table 1). Betweenvisit repeatability was good at both time intervals for most IOS and MBW parameters, with ICC values $>0.8$ in the majority of cases. However, the repeatability of Scond and Sacin at 3 months was only moderate, with ICC values of 0.63 and 0.71 respectively. Within-visit repeatability was also assessed using the ICC of triplicate tests performed at baseline. All physiological measurements had high within-visit repeatability (ICC >0.85), with the exception of Scond. Previous investigators have also noted the poor within-visit repeatability of Scond [12], suggesting that this parameter may be less suitable than LCI and Sacin as an outcome measure in clinical trials.

The mean, standard deviation and 95\% confidence intervals of between-visit differences are shown in table 1 . The standard deviation data may be used, in conjunction with estimates of the minimal clinically important difference (MCID), to perform sample size calculations for interventional studies in patients with asthma. Given a parallel group study design in which the change in the variable of interest from baseline to follow-up is compared between an intervention and a control group using a parametric test, the required sample size may be calculated using a standard formula [13]. Although the MCID has not been established for most small airway outcome measures, estimates can be made from previously published data. YAMAGUCHI et al. [14] compared the response to small-particle and standard corticosteroid inhalers in steroid-naïve asthmatics using IOS. They observed a reduction in $R 5$ minus $R 20$ of $0.05 \mathrm{kPa} \cdot \mathrm{L}^{-1} \cdot \mathrm{s}$ in the small-particle group and $0.02 \mathrm{kPa} \cdot \mathrm{L}^{-1} \cdot \mathrm{s}$ in the standard group, thus giving a difference between groups of $0.03 \mathrm{kPa} \cdot \mathrm{L}^{-1} \cdot \mathrm{s}$ with respect to the change in $R 5-R 20$ from baseline to follow-up. The sample size required to detect this difference following a 2 -week treatment period with $80 \%$ power and $5 \%$ two-tailed significance would be 28 per treatment arm, which would be feasible in most clinical trial settings.

A potential limitation of our study was the relatively high mean age of our participants. It is possible that younger patients with asthma manifest a greater degree of variability in airway function than older patients, and further studies are required to investigate this possibility. However, the relative preponderance of middle-aged patients in our participant group is typical of previously described refractory asthma cohorts [15], and is thus representative of patients most likely to be enrolled in clinical trials. As expected, variability was greater at 3 months than at 2 weeks for most outcome measures. However, LCI was a notable exception to this pattern. We therefore recommend that the 2-week estimate of variability be used for all sample size calculations involving LCI, in order to mitigate the risk of the study being underpowered.

We conclude that IOS parameters are stable over time and have potential as outcome measures in clinical asthma trials. MBW indices are moderately stable but require further investigation in patients with asthma. Further studies are required to determine the longer-term variability of MBW and IOS parameters, as well as to establish the MCID for a number of small airway outcome measures.

TABLE 1 Between-visit variability of physiological variables in patients with asthma

Baseline values

$\overline{\text { Mean } \pm S D \quad I C C^{\#}}$

Variability at 2 weeks

$\begin{gathered}\text { Mean } \pm \text { SD change from } \\ \text { baseline }(95 \% \mathrm{CI})\end{gathered}$
ICC

\begin{tabular}{cccccc} 
Variability at 2 weeks & & & \multicolumn{2}{c}{ Variability at 3 months } \\
\cline { 1 - 1 } \cline { 5 - 6 } $\begin{array}{c}\text { Mean } \pm \text { SD change from } \\
\text { baseline }(95 \% \text { CI) }\end{array}$ & ICC & & $\begin{array}{c}\text { Mean } \pm \text { SD change from } \\
\text { baseline }(95 \% \text { CI) }\end{array}$ & ICC \\
$0.02 \pm 0.64(-1.24-1.28)$ & 0.83 & & $0.04 \pm 0.85(-1.63-1.71)$ & 0.78 \\
$-0.04 \pm 0.14(-0.32-0.24)$ & 0.98 & & $0.04 \pm 0.18(-0.33-0.40)$ & 0.98 \\
$-0.15 \pm 0.50(-1.13-0.82)$ & 0.94 & & $-0.07 \pm 0.58(-1.20-1.06)$ & 0.94 \\
$-0.02 \pm 0.08(-0.18-0.14)$ & 0.89 & & $-0.02 \pm 0.09(-0.21-0.16)$ & 0.86 \\
$-0.01 \pm 0.06(-0.12-0.10)$ & 0.88 & & $-0.02 \pm 0.06(-0.14-0.10)$ & 0.85 \\
$-0.02 \pm 0.04(-0.09-0.06)$ & 0.91 & & $-0.01 \pm 0.05(-0.12-0.10)$ & 0.84 \\
$0.02 \pm 0.05(-0.08-0.11)$ & 0.88 & & $0.03 \pm 0.06(-0.08-0.15)$ & 0.80 \\
$-0.25 \pm 0.59(-1.40-0.91)$ & 0.88 & & $-0.23 \pm 0.67(-1.54-1.09)$ & 0.86 \\
$0.14 \pm 1.04(-1.89-2.18)$ & 0.78 & & $-0.25 \pm 0.63(-1.48-0.99)$ & 0.91 \\
$0.004 \pm 0.038(-0.072-0.079)$ & 0.89 & & $-0.007 \pm 0.057(-0.119-0.104)$ & 0.63 \\
$-0.024 \pm 0.067(-0.156-0.108)$ & 0.83 & & $-0.027 \pm 0.068(-0.16-0.11)$ & 0.71 \\
\hline
\end{tabular}

ICC: intraclass correlation coefficient; $A C Q-6$ : six-point Asthma Control Questionnaire; FEV1: forced expiratory volume in 1 s; MEF50: midexpiratory flow at $50 \%$ of vital capacity; R5: resistance at $5 \mathrm{~Hz} ; R_{20}$ : resistance at $20 \mathrm{~Hz} ; R 5-R 20$ : resistance at $5 \mathrm{~Hz}$ minus resistance at $20 \mathrm{~Hz}$; X5: reactance at $5 \mathrm{~Hz}$; Ax: reactance area; $\mathrm{LCl}$ : lung clearance index; Scond: conductive ventilation heterogeneity; Sacin: acinar ventilation heterogeneity. ${ }^{\#}$ : of triplicate tests performed at baseline; ": of tests performed at baseline versus follow-up visits. 
@ERSpublications

Small airway obstruction markers are stable over time and have potential as outcome measures in clinical trials http://ow.ly/tCzp2

Sherif Gonem ${ }^{1}$, Steven Corkill ${ }^{1}$, Amisha Singapuri ${ }^{1}$, Per Gustafsson ${ }^{2}$, Rino Costanza ${ }^{3}$, Christopher E. Brightling ${ }^{1}$ and Salman Siddiqui ${ }^{1}$

${ }^{1}$ Institute for Lung Health, Dept of Infection, Immunity and Inflammation, University of Leicester, Leicester, and ${ }^{3}$ Chiesi Ltd, Cheadle, UK. ${ }^{2}$ Dept of Paediatrics, Central Hospital, Skövde, Sweden.

Correspondence: Sherif Gonem, Respiratory Research BRU, Glenfield Hospital, Groby Road, Leicester, LE3 9QP, UK. E-mail: sg330@le.ac.uk

Received: Jan 032014 | Accepted after revision: Feb 082014 | First published online: March 062014

Support statement: This article presents independent research funded by the National Institute for Health Research (NIHR). The views expressed are those of the authors and not necessarily those of the National Health Service, the NIHR or the Dept of Health. This work was partly funded through research collaborations with Chiesi Farmaceutici SPA. Additional funding was received from the Airway Disease Predicting Outcomes through Patient Specific Computational Modelling (AirPROM) project (funded through FP7 European Union grant 270194).

Conflict of interest: Disclosures can be found alongside the online version of this article at www.erj.ersjournals.com

\section{References}

1 van den Berge M, ten Hacken NH, van der Wiel E, et al. Treatment of the bronchial tree from beginning to end: targeting small airway inflammation in asthma. Allergy 2013; 68: 16-26.

2 Goldman MD, Saadeh C, Ross D. Clinical applications of forced oscillation to assess peripheral airway function. Respir Physiol Neurobiol 2005; 148: 179-194.

3 Robinson PD, Latzin P, Verbanck S, et al. Consensus statement for inert gas washout measurement using multipleand single- breath tests. Eur Respir J 2013; 41: 507-522.

4 Gonem S, Natarajan S, Desai D, et al. Clinical significance of small airway obstruction markers in patients with asthma. Clin Exp Allergy 2014; 44: 499-507.

5 Farah CS, King GG, Brown NJ, et al. The role of the small airways in the clinical expression of asthma in adults. J Allergy Clin Immunol 2012; 129: 381-387.

6 Global Initiative for Asthma. Global Strategy for Asthma Management and Prevention. www.ginasthma.org/local/ uploads/files/GINA_Report_March13.pdf Date last updated: 2012.

7 British Thoracic Society. Asthma Guideline. www.brit-thoracic.org.uk/guidelines-and-quality-standards/asthmaguideline/ Date last updated: January 2012.

8 Juniper EF, Svensson K, Mörk AC, et al. Measurement properties and interpretation of three shortened versions of the asthma control questionnaire. Respir Med 2005; 99: 553-558.

9 Oostveen E, MacLeod D, Lorino $\mathrm{H}$, et al. The forced oscillation technique in clinical practice: methodology, recommendations and future developments. Eur Respir J 2003; 22: 1026-1041.

10 Horsley AR, Gustafsson PM, Macleod KA, et al. Lung clearance index is a sensitive, repeatable and practical measure of airways disease in adults with cystic fibrosis. Thorax 2008; 63: 135-140.

11 Verbanck S, Schuermans D, van Muylem A, et al. Ventilation distribution during histamine provocation. J Appl Physiol 1997; 83: 1907-1916.

12 Horsley AR, Macleod KA, Robson AG, et al. Effects of cystic fibrosis lung disease on gas mixing indices derived from alveolar slope analysis. Respir Physiol Neurobiol 2008; 162: 197-203.

13 Kirkwood BR, Sterne JAC. Essential Medical Statistics, 2nd Edn. Oxford, Blackwell Publishing Ltd, 2003; pp. 420-421.

14 Yamaguchi M, Niimi A, Ueda T, et al. Effect of inhaled corticosteroids on small airways in asthma: investigation using impulse oscillometry. Pulm Pharmacol Ther 2009; 22: 326-332.

15 Heaney LG, Brightling CE, Menzies-Gow A, et al. Refractory asthma in the UK: cross-sectional findings from a UK multicentre registry. Thorax 2010; 65: 787-794.

\section{Bronchial obstruction and reversibility in children: inspiratory or expiratory resistance?}

To the Editor:

Assessing bronchial obstruction and reversibility is of help in diagnosing asthma. The forced oscillation technique (FOT) has gained popularity in children since minimal cooperation is required. Owing to the fact 